\title{
Strain Variation of Lyme Disease Spirochetes Isolated from Ixodes ricinus Ticks and Rodents Collected in Two Endemic Areas in Switzerland
}

\author{
PIERRE-FRANCOIS HUMAIR, ${ }^{1}$ OLIVIER PETER, ${ }^{2}$ REINHARD WALLICH, ${ }^{3}$ \\ AND LISE GERN ${ }^{1}$
}

\begin{abstract}
J. Med. Entomol. 32(4): 433-438 (1995)
ABSTRACT The relationship among Lyme borreliosis, Borrelia genospecies, rodent reservoirs, and Ixodes ricinus L. ticks was studied in two endemic areas in Switzerland. Ear punch biopsies and sampling of internal organs were used to isolate Borrelia burgdorferi (Johnson, Schmid, Hyde, Steigerwalt and Brenner) from small mammals, Apodemus sylvaticus L., A. flavicollis Melchior, Clethrionomys glareolus Schreber. Spirochetes were isolated from ear tissue and spleen of the rodents. Isolates were homogeneous and belonged to typing group II identified as B. afzelii (Canica, Nato, du Merle, Mazie, Baranton and Postic). Our data show that a specific association exists between B. afzelii and rodent reservoirs in European foci. Borreliae were also isolated from field-collected $I$. ricinus ticks from the same study areas. Proteinic and antigenic analysis indicated that more than one genospecies were present in the tick population. This suggests that other vertebrate hosts may serve as reservoirs of other Borrelia genospecies implicated with Lyme disease.
\end{abstract}

KEY WORDS Lyme borreliosis, Borrelia afzelii, rodents

Borrelia burgdorferi Johnson, Schmid, Hyde, Steigerwalt and Brenner, the causative agent of Lyme borreliosis, is maintained in nature by tickvertebrate transmission. In European endemic foci, the three-host tick Ixodes ricinus $\mathrm{L}$. is involved in the maintenance cycle, transmitting the spirochetes to animal hosts that serve as sources for infecting other ticks. Larvae mainly feed on small mammals, whereas nymphs are more frequently found on birds and medium-sized mammals (Aeschlimann 1972). In Switzerland, the prevalence of infected questing larval ticks is low (3.1\%) (Miserez et al. 1990, Zhioua et al. 1994), whereas the infection rates of $B$. burgdorferi in host-seeking nymphs and adults range from 10 to 55\% (Aeschlimann et al. 1986, Miserez et al. 1990, Péter 1990, Lebet and Gern 1994, Leuba-Garcia et al. 1994). Rodents including Apodemus flavicollis Melchior, A. sylvaticus L., and Clethrionomys glareolus Schreber were shown to be reservoir hosts because they may remain infective for ticks for a long time after the primary infection (Aeschlimann et al. 1986, Humair et al. 1993a, Gern et al. 1994b).

Lyme spirochetes have shown a great diversity concerning their pheno- and genotypic characters (Barbour et al. 1985, Wilske et al. 1988, Kramer et al. 1990, Péter and Bretz 1992, Wallich et al.

\footnotetext{
1 Institut de Zoologie, Université de Neuchâtel, 2007 Neuchâtel, Switzerland.

Institut Central des Hôpitaux Valaisans, 1950 Sion, Switzerland.

${ }^{3}$ Angewandte Immunologie, FS 0440, Deutsches Krebsforschungszentrum, 6900 Heidelberg, Germany.
}

1992). Using various methods, three genospecies have now been described in Europe: $B$. burgdorferi sensu stricto, B. garinii Baranton, Postic, Saint Girons, Boerlin, Piffaretti, Assous and Grimont, and $B$. afzelii Canica, Nato, du Merle, Mazie, Baranton and Postic (Baranton et al. 1992, Canica et al. 1993). These genomic species can be routinely identified by monoclonal antibodies (Canica et al. 1993). Besides, recent studies have demonstrated that various phenotypes of $B$. burgdorferi are present in the tick population of one endemic area (Péter and Bretz 1992, Boerlin et al. 1992) and that their distribution greatly differ from one area to another ( $\mathrm{Hu}$ et al. 1994a). The reason for such a diversity in a focus remains unknown but could be caused by the presence and frequency of various reservoir hosts.

In this study, we were interested in isolating spirochetes from rodents and from host-seeking ticks collected in two endemic areas to compare their phenotypic characteristics.

\section{Materials and Methods}

Study Sites. Collection of rodents and ticks were conducted in two endemic woodlands in Switzerland: Glütschbachtal near Thun (site A) (Canton of Berne, altitude $589 \mathrm{~m}$ ) and a forest close to Martigny (site B) (Canton of Valais, altitude $484-500 \mathrm{~m}$ ).

Investigation of Rodents. Small mammals were live-trapped at both study sites from May to October 1993. Traps baited with cereal granules, sunflower grains, and apples were set once monthly in 
the evening and checked the two following mornings. Captured rodents were brought to the laboratory and caged individually. Animals were identified to species on the basis of morphometric measurements and pelage coloration, identified by sex, and weighed.

Animals from site A were anesthetized, marked, and an ear punch biopsy was performed for isolation of $B$. burgdorferi. Rodents were finally released at the site where they were captured. Animals from site B were killed by carbon dioxide inhalation in an euthanasia chamber and dissected. Cultures were prepared from samples of bladder, spleen, heart, brain, cheek skin, and ear.

Animal care and manipulations were in accordance with the Swiss Federal Animal Welfare Laws (LPA and OPA). This study was conducted in accordance with the permits issued by the Swiss Federal Forest Department and the Cantonal Department of Agriculture.

Collections of Ticks. Nymphal and adult I. ricinus ticks were collected from vegetation by flagging. One-hour flagging was done once a month at Glütschbachtal, during August-October 1993. Ticks collected were identified to species, stage, and sex.

Isolation of Spirochetes. Ear samples were removed from anesthetized animals after cleaning the ear with $70 \%$ ethanol. Ear punch biopsies and dissected tissues from bladder, cheek skin, heart, spleen, and brain were placed into tubes containing supplemented Barbour Stoenner Kelly (BSKII) medium as described by Sinsky and Piesman (1989).

Field-collected ticks were briefly soaked in $70 \%$ ethanol before they were individually squashed with sterilized forceps in tubes containing BSKII medium (Barbour 1984) supplemented with $50 \mu \mathrm{g} /$ $\mathrm{ml}$ Rimactan (Ciba, Basel, Switzerland) and $50 \mu \mathrm{g} /$ $\mathrm{ml}$ Fosfocin (Boehringer, Mannheim, Germany).

Dark-field microscopy was used to screen inoculated cultures for the presence of spirochetes after $10 \mathrm{~d}$, and 3,6 , and $8 \mathrm{wk}$ of incubation at $34^{\circ} \mathrm{C}$. Positive cultures were inoculated into fresh tubes of BSKII medium (Barbour 1984) for additionnal growth and evaluation by sodium dodecyl sulfatepolyacrylamide gel electrophoresis (SDS-PAGE), Western blot and Southern blot.

Sodium Dodecyl Sulfate-Polyacrylamide Gel Electrophoresis. Electrophoresis and immunoblots were performed as previously described (Péter and Bretz 1992). In short, the suspension of washed borreliae $(1 \mathrm{mg} / \mathrm{ml})$ were dissolved (1:1) in the sample buffer with $0.6 \%$ sodium dodecyl sulfate (SDS) (final concentration) and $50 \mathrm{mM}$ dithiothreitol as a reducing agent. The samples were boiled for $5 \mathrm{~min}$ before undergoing electrophoresis (constant current $45 \mathrm{~mA}$ ) on polyacrylamide gel at $12.5 \%$ for the separating gel and a $4 \%$ stacking gel, according to the method described by Barbour et al. (1985). The standard molecular weights (MW) of BioRad (low range protein molecular weight standards) were used as reference for the calculation of relative molecular weights. After electrophoresis, proteins were transferred by Western blot to polyvinylidene difluoride (PVDF) membrane (Immobilon, Millipore, Kloten, Switzerland) in accordance with the method of Towbin et al. (1979).

Immunoblotting and Typing of Isolates. After transfer, the membrane was stained with Coomassie blue. The membrane was then cut at the level of the outer surface proteins OspA and OspB as well as below 14.4-kDa marker, and these two pieces were destained in a bath of pure methanol for a few seconds. They were saturated with $3 \%$ gelatine in a Tris buffer of $\mathrm{pH} 7.5$ for $1 \mathrm{~h}$ at $37^{\circ} \mathrm{C}$ and washed three times for $5 \mathrm{~min}$ in a Tris-Tween $20(0.05 \%)$ buffer. The piece containing the OspA and OspB were incubated for $2 \mathrm{~h}$ at room temperature with monoclonal antibodies (MAbs) H3TS and I 17.3 diluted 1:500 and 1:500 000, respectively, in the same buffer with additional $1 \%$ gelatine. The piece below $14.4 \mathrm{kDa}$ was incubated as above with monoclonal antibody D6 diluted 1: 100. After washing, MAbs fixed specifically on the antigens were demonstrated by a second goat antimouse IgG for H3TS and I 17.3 MAb or goat antimouse IgM for D6 MAb conjugated to alcaline phosphatase, followed by three washes and the addition of BCIP/NBT substrate (5 bromo-4-chloro3-indoyl p-toluidine phosphate/p-nitro blue tetrazolium chloride).

Southern Blot Hybridization. Total genomic DNA was extracted from Borrelia organisms as described previously (Wallich et al. 1992). Briefly, about $5 \mu \mathrm{g}$ of DNA was digested with 100 units of restriction nuclease HindIII according to manufacturer recommendations (Boehringer). Samples were electrophorized using a $0.7 \%$ agarose gel. DNA fragments were transferred to Hybond-N nylon membrane (Amersham Buchler, Braunschweig, Germany) followed by UV-cross-linking and hybridization as described (Wallich et al. 1992). Shortly, using ${ }^{32} \mathrm{P}$-labeled ospa gene probe, hybridization was performed overnight at $65^{\circ} \mathrm{C}$ in $0.5 \mathrm{M} \mathrm{NaHPO} / 7 \%$ NaDodSO, $7.2 \mathrm{pH}$. After washing in $40 \mathrm{mM} \mathrm{NaHPO} / 1 \% \mathrm{NaDodSO}_{4}, 7.2$ $\mathrm{pH}$ at room temperature for $30 \mathrm{~min}$, the dry membrane was autoradiographed on Kodak XAR-5 film with intensifying screens at $-80^{\circ} \mathrm{C}$ for $1-12 \mathrm{~h}$.

\section{Results}

Rodent Isolates. In total, 111 small mammals were captured from May through October 1993 at Glütschbachtal near Thun (site A): $60 \mathrm{C}$. glareolus, 22 A. flavicollis, 21 A. sylvaticus, 2 Apodemus sp., and 6 Sorex araneus L. In Martigny (site B), 41. small mammals were captured: 31 A. flavicollis, 9 A. sylvaticus, and 1 Glis glis $\mathrm{L}$.

In site $\mathrm{A}$, ear punch biopsies were removed from 55 C. glareolus, 22 A. flavicollis, 21 A. sylvaticus, and 2 Apodemus sp. Fourteen isolates of borreliae 

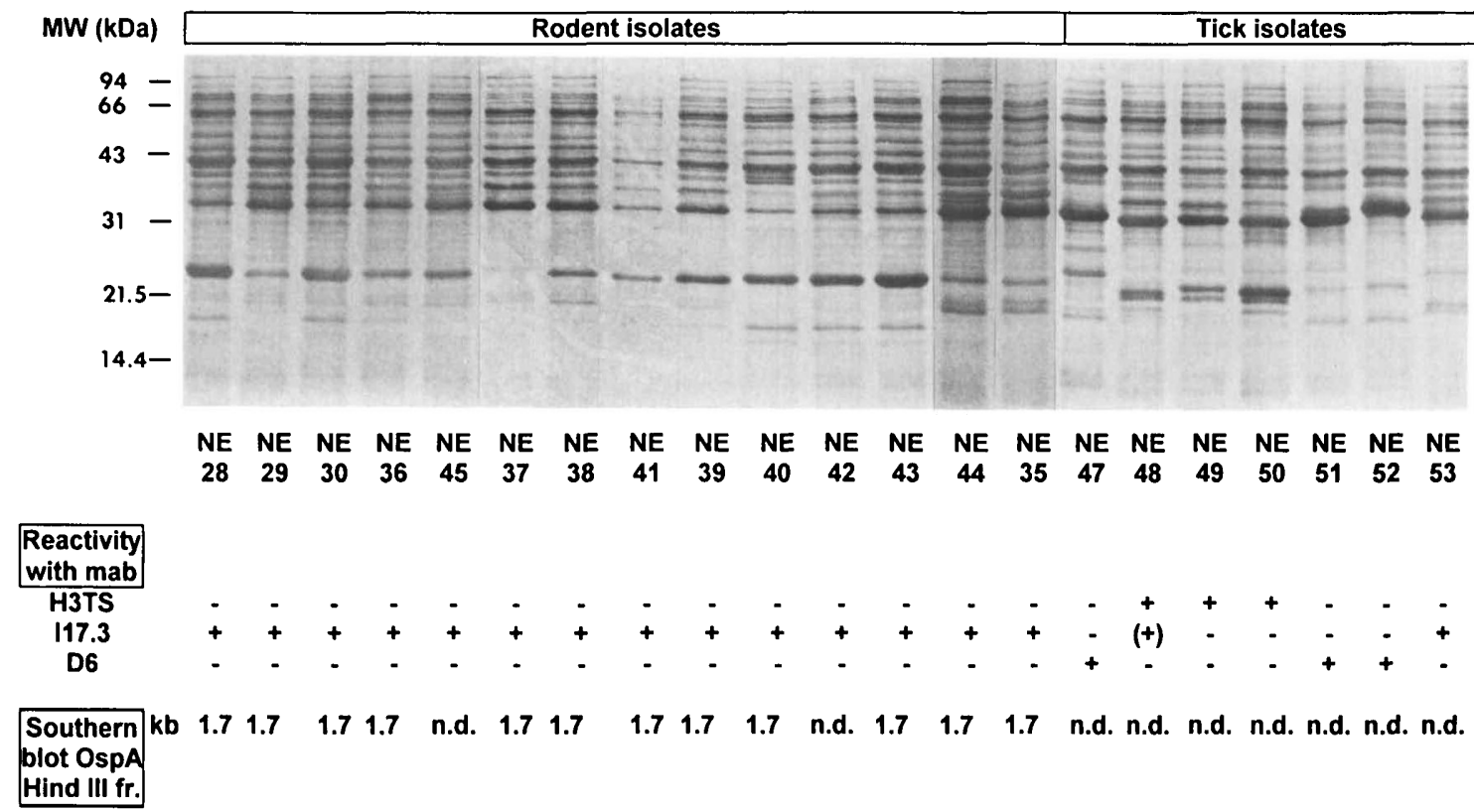

Fig. 1. Protein profiles of Borrelia isolates from rodents and ticks from site A. Immunoblotting: reactivity with monoclonal antibodies H3TS (anti-B. burgdorferi sensu stricto), I 17.3 (anti-B. afzelii), and D6 (anti-B. garinii). Southern blotting: size (kb) of HindIII fragment for the ospA gene. MW, molecular weight standard; NE28-NE30 and NE36-NE45, isolates from C. glareolus voles; NE35, isolate from A. flavicollis mouse; NE47-NE49, isolates from I. ricinus females; NE50-NE52, isolates from I. ricinus males; NE53, isolate from I. ricinus nymph. + , positive reaction; (+), lightly positive reaction; - , negative reaction; n.d., not done.

were cultivated from ear tissue biopsies of $10 \mathrm{C}$. glareolus (NE28-30 and NE36-45) and 1 A. flavicollis (NE35) (Fig. 1). Three isolates (NE30, NE36, and NE45) were obtained from one $C$. glareolus captured in June (NE30), recaptured in July (NE36), and maintained in the laboratory until October (NE45). Two isolates (NE38 and NE41) were obtained from another vole trapped in July (NE38) and retrapped in August (NE41).

In site $\mathrm{B}$, two isolates of borreliae were cultivated, one from the ear biopsy of one A. flavicollis (VS 25R) and the other from the spleen tissue of one A. sylvaticus (VS 42R) (Fig. 2).

Protein profiles (Figs. 1 and 2) showed a great homogeneity. All rodent isolates possessed an OspA of $32 \mathrm{kDa}$ and an OspB of $35 \mathrm{kDa}$. A major band of $23 \mathrm{kDa}$ was generally visible, except in two cases (Fig. 1: lane 6, NE37 and Fig. 2: lane 2, VS 42R). By Western blotting, all rodent isolates reacted with MAb I 17.3 which recognizes B. afzelii, but did not react with MAb H3TS which specifically reacts with $B$. burgdorferi sensu stricto or MAb D6 which identifies $B$. garinii isolates (Figs. 1 and 2).

Southern blotting confirmed the homogeneity of the rodent isolates from site A (Fig. 1). All showed a single DNA fragment of $1.7 \mathrm{~kb}$ for the ospA gene as the strain ACA1 (Wallich et al. 1992).
Tick Isolates. The cultivation of 40 I. ricinus (22 nymphs, 11 females, and 7 males) from site $\mathrm{A}$ yielded seven isolates, three from females (NE4749), three from males (NE50-52), and one from a nymph (NE53). From site B, six isolates were obtained from 55 adults, three from females (VS 134, 137, and 641), and three from males (VS 14, 619, and 623).

Protein profiles of tick isolates (Fig. 1) from site A clearly showed a heterogeneous pattern. The OspA, varying between 31 and $33 \mathrm{kDa}$, was always present, whereas the OspB $(33-35 \mathrm{kDa})$ was not expressed in two isolates (lanes 19 and 20, respectively NE51 and NE52). The 21.5-24 kDa proteins of tick isolates presented a bigger variability than that of rodent isolates.

Using Western blotting, two tick isolates-one from a female (NE48) and one from a nymph (NE53)_reacted with MAb I 17.3, which recognizes B. afzelii (Fig. 1). Three tick isolates (NE47, $\mathrm{NE51}$, and NE52) reacted with MAb D6, which specifically identifies $B$. garinii. Reactivity with MAb H3TS, which recognizes $B$. burgdorferi sensu stricto, occurred three times among tick isolates: two from females (NE48 and NE49) and one from a male (NE50). Hence, NE48 reacted with both H3TS and I 17.3, suggesting that both genospecies were present in this female tick. Immunoblot of 


\section{SITE B}
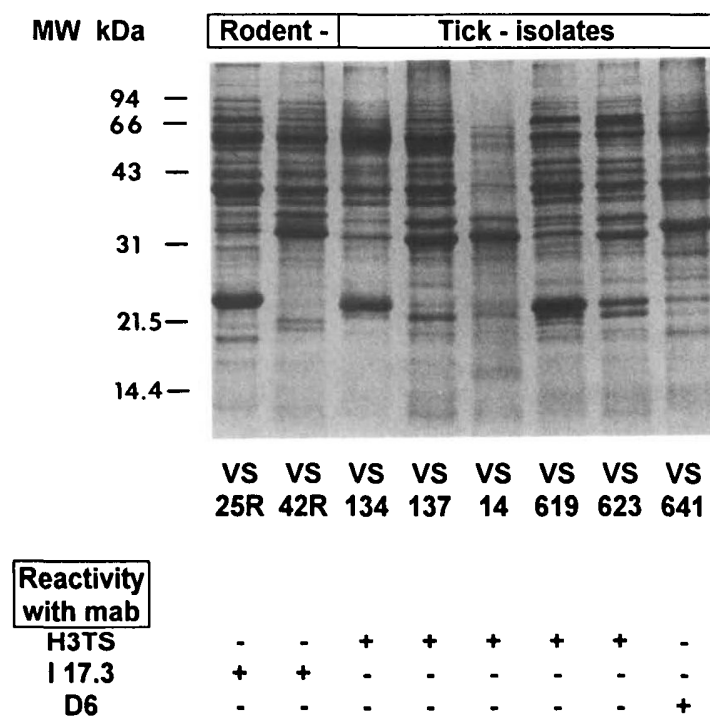

Fig. 2. Protein profiles of Borrelia isolates from rodents and ticks from site B. Immunoblotting: reactivity with monoclonal antibodies H3TS (anti- $B$. burgdorferi sensu stricto), I 17.3 (anti-B. afzelii), and D6 (anti-B. garinii). MW, molecular weight standard; VS $25 \mathrm{R}$, isolate from A. flavicollis mouse; VS 42R, isolate from A. sylvaticus mouse; VS 134, VS 137, and VS 641, isolates from I. ricinus females; VS 14 , VS 619 , and VS 623 , isolates from $I$. ricinus males.

NE48 isolate from a previous subculture (data not shown) showed a stronger reactivity with I 17.3 than with H3TS (immunoreactivity reversed in comparison to Fig. 1, NE48), suggesting that competition between strains may occur during cultivation.

Five of the isolates from site B showed protein profiles (Fig. 2) with an OspA of $31 \mathrm{kDa}$ and an OspB of $34 \mathrm{kDa}$. The remaining isolate had an OspA of $32 \mathrm{kDa}$ but no OspB (Fig. 2). Immunoblotting with MAb H3TS confirmed that the five isolates were $B$. burgdorferi sensu stricto and the other one reacted with MAb D6, specific for $B$. garinii isolates. None reacted with MAb I 17.3.

\section{Discussion}

This study was prompted by the results of a previous investigation showing that various $B$. burgdorferi strains may be present in an endemic area (Boerlin et al. 1992, Péter and Bretz 1992) and that some phenotypes may be more frequent in some foci than in others ( $\mathrm{Hu}$ et al. 1994a). In nature, $B$. burgdorferi is maintained by tick-vertebrate transmission. Spirochetes present in ticks originate from hosts on which the ticks fed during their previous blood meal. Because rodents are competent amplifying hosts capable of transmitting spirochetes to a great number of larvae (Aeschli- mann et al. 1986, Kurtenbach et al. 1992, Humair et al. 1993a, Gern et al. 1994b), we were interested in the phenogenotypes of spirochetes infecting small mammals.

In Europe, a great heterogeneity in the expression of the main outer surface proteins (Osp) of $B$. burgdorferi is present among tick and patient isolates. However, little is known about the quality of the spirochetes infecting wild mammals; only two isolations from rodents have been described so far (Hovmark et al. 1988). In the current study, a total of 16 isolates was obtained from ear punch biopsies or spleen of Apodemus mice and Clethrionomys voles. All were homogeneous and belonged to typing group II (Péter and Bretz 1992), which is now referred to as $B$. afzelii (Canica et al. 1993). Interestingly, the rodent isolate $(\mathrm{SmS1})$ obtained by Hovmark et al. (1988) belongs to B. afzelii (Postic et al. 1994) as well as two strains isolated from rodents in Northern Italy (Genchi et al. 1994).

The first description of the ear punch biopsy method for isolation of $B$. burgdorferi showed that this method is appropriate for isolation of $B$. burgdorferi sensu stricto from hamsters and Peromyscus leucopus Rafinesque (Sinsky and Piesman 1989). Isolates obtained from ear punch biopsies of laboratory mice infected by the European strain ZS7 (Gern et al. 1994a), which was identified as B. burgdorferi sensu stricto (Wallich et al. 1992), confirm that no selection process caused by the medium is responsible for such an homogeneity among our rodent isolates.

However, recent studies (Gorelova et al. 1994, Khanakah et al. 1994) have shown that the different genospecies of the causative agent of Lyme disease were isolated by culture or detected by polymerase chain reaction in the internal organs of small mammals (urinary bladder, heart, spleen). Thus, a single rodent may be infected by more than one genospecies (Khanakah et al. 1994). The results of the current study reveal that only one genospecies, $B$. afzelii, is prominent in the ears of the rodents. This suggests that $B$. afzelii would demonstrate preferentially a cutaneous location in rodents, as observed in human skin lesions (Canica et al. 1993). This fact is epizootiologically important, because ticks feeding on rodents attach primarily to the ears (Arthur 1965). Thus, one would assume that ticks that had fed on infected rodents would harbor B. afzelii. This was confirmed by $\mathrm{Hu}$ et al. (1994b) who observed that isolates obtained from ticks that had been allowed to feed on infected Apodemus sp. mice were B. afzelii. Additionally, isolates from rodent-feeding Ixodes persulcatus Schulze in Japan were identified as $B$. afzelii (Nakao et al. 1994). Finally, even if rodents may be infected by a different genospecies of $B$. burgdorferi, our data coupled with those of $\mathrm{Hu}$ et al. (1994b), strongly suggest that a specific association exists between the type strain and Apodemus mice and Clethrionomys voles that appear to be the main reservoirs for the genospecies $B$. afzelii. 
Isolate's from host-seeking ticks were heterogeneous: the three genospecies were represented. This confirms the results observed in previous studies, showing a great diversity among $B$. burgdorferi strains isolated from ticks from endemic foci (Hu et al. 1994a; O.P., unpublished data). One of the female ticks collected in Thun was infected by more than one phenotype. This is in accordance with previous observations showing that adults may harbor more than one genospecies (Leuba-Garcia et al. 1994).

The heterogeneity of tick isolates contrasts the homogeneity of isolates from rodents. Our data indicate an association in nature between the genospecies B. afzelii and rodents, and suggest that other genospecies may be associated with other vertebrate hosts. Ground-foraging birds (e.g., thrushe's, blackbirds, and robins) have been incriminated as potential reservoirs for the Lyme disease spirochete (Humair et al. 1993b) and could be associated with $B$. garinii. The recent observations of $B$. garinii in bird-feeding ticks (Nakao et al. 1994, Olse'n et al. 1994) support such a hypothesis.

Further studies are needed to investigate the role of other potential hosts to understand the relationship between Borrelia genospecies and vertebrate reservoirs.

\section{Acknowledgments}

We thank Christiane Brenner, Anne-Gabrielle Bretz, Mafalda Vieira da Silva, and Olivier Rais for their excellent technical assistance, and Alan Barbour and Guy Baranton for the monoclonal antibodies. This research was supported by the Swiss National Science Foundation (No. 32-29964-90) and the Swiss Federal Office of Education and Science (No. 93.0363). This work is part of the Ph.D. dissertation of P.F.H.

\section{References Cited}

Aeschlimann, A. 1972. Ixodes ricinus, Linné, 1758 (Ixodoidea: Ixodidae). Essai préliminaire de synthèse sur la biologie de cette espèce en Suisse. Acta Trop. 29: $321-340$.

Aeschlimann, A., E. Chamot, F. Gigon, J.-P. Jeanneret, D. Kesseler, and C. Walther. 1986. B. burgdorferi in Switzerland. Zentralbl. Bakteriol. Mikrobiol. Hyg. Ser. A 263: 450-458.

Arthur, D. R. 1965. Feeding in ectoparasitic Acari with special reference to ticks. Adv. Parasitol. 3: 249298.

Baranton, G., D. Postic, I. Saint Girons, P. Boerlin, J.-C. Piffaretti, M. Assous, and P.A.D. Grimont. 1992. Delineation of Borrelia burgdorferi sensu stricto, Borrelia garinii sp. nov., and group VS461 associated with Lyme borreliosis. Int. J. Syst. Bacteriol. 42: $378-383$.

Barbour, A. G. 1984. Isolation and cultivation of Lyme disease spirochetes. Yale J. Biol. Med. 57: 521-525.

Barbour, A. G., R. A. Heiland, and T. R. Howe. 1985. Heterogeneity of major protein in Lyme disease borreliae: a molecular analysis of North Ameri- can and European isolates. J. Infect. Dis. 152: 478484.

Boerlin, P., O. Péter, A. G. Bretz, D. Postic, G. Baranton, and J.-C. Piffaretti. 1992. Population genetic analysis of Borrelia burgdorferi isolates in multilocus enzyme electrophoresis. Infect. Immun. 40: $1677-1683$.

Canica, M. M., F. Nato, L. du Merle, J. C. Mazie, G. Baranton, and D. Postic. 1993. Monoclonal antibodies for identification of $B$. afzelii $\mathrm{sp}$. nov. associated with late cutaneous manifestations of Lyme borreliosis. Scand. J. Infect. Dis. 25: 441-448.

Genchi, C., A. P. Rizzoli, M. Fabbi, V. Sambri, M. T. Manfredi, S. Magnino, A. Moroni, F. Massaria, and R. Cevenini. 1994. Ecology of Borrelia burgdorferi in some areas of Northern Italy, pp. 232-235. In Proceedings of the VI Intemational Conference on Lyme Borreliosis, Bologna, Italy, June 19-22, 1994. R. Cevenini, V. Sambri, and M. La Placa [eds.], Bologna.

Gern, L., O. Rais, C. Capiau, P. Hauser, Y. Lobet, E. Simoen, P. Voet, and J. Pêtre. 1994a. Immunization of mice by recombinant OspA preparations and protection against Borrelia burgdorferi infection induced by Ixodes ricinus bites. Immunol. Lett. 39: 249-258.

Gern, L., M. Siegenthaler, C. M. Hu, S. Leuba-Garcia, and P. F. Humair. 1994b. Borrelia burgdorferi in rodents (Apodemus flavicollis and A. sylvaticus): Duration and enhancement of infectivity for Ixodes ricinus ticks. Eur. J. Epidemiol. 10: 75-80.

Gorelova, N. B., E. I. Korenberg, Y. V. Kovalevsky, and S. V. Sheherbakov. 1994. Isolation of Burrelia from small mammals that inhabit regions adjoining the Urals (Russia). VI International Conference on Lyme Borreliosis, Bologna, Italy, June 19-22, 1994. Abstract P059W. R. Cevenini, V. Sambri, and M. Ia Placa [eds.], Bologna.

Hovmark, A., T.G.T. Jaenson, E. Åshrink, A. Forsman, and E. Jansson. 1988. First isolations of Borrelia burgdorferi from rodents collected in Northern Europe. Acta Pathol. Microbiol. Immunol. Scand. Sect B 96: 917-920.

Hu, C. M., S. Leuba-Garcia, A. Aeschlimann, M. D. Kramer, and L. Gern. 1994a. Comparison in the immunological properties of Borrelia burgdorferi isolates from Ixodes ricinus between three endemic areas in Switzerland. Epidemiol. Infect. 11.2: 533-542.

Hu, C. M., P. F. Humair, S. Leuba-Garcia, M. D. Kramer, and L. Gern. 1994h. Analysis of Borrelia burgdorferi isolates from rodents and free-living ticks from an endemic area in Switzerland. VI International Conference on Lyme Borreliosis, Bologna, Italy, June 19-22, 1994. Abstract P071W. R. Cevenini, V. Sambri and M. La Placa [eds.], Bologna.

Humair, P. F., N. Turrian, A. Aeschlimann, and L. Gern. 1993a. Borrelia burgdorferi in a focus of Lyme borreliosis: the epizootiologic contribution of small mammals. Folia Parasitol. 40: 65-70.

1993b. Ixodes ricinus immatures on birds in a focus of Lyme borreliosis. Folia Parasitol. 40: 237-242.

Khanakah, G., E. Kmety, A. Radda, and G. Stunek. 1994. Micromammals as reservoir of Borrelia burgdorferi in Austria. VI International Conference on Lyme Borreliosis, Bologna, Italy, June 19-22, 1994. Abstract P077W. R. Cevenini, V. Sambri, and M. La Placa [eds.], Bologna.

Kramer, M. D., U. E. Schaible, R. Wallich, S. E. Moter, D. Petzoldt, and M. M. Simon. 1990. Char- 
acterization of Borrelia burgdorferi associated antigens by monoclonal antibodies. Immunobiology 181: $357-366$.

Kurtenbach, K., A. Dizij, H. Kampen, S. Moter, R. Wallich, U. E. Schaible, and M. M. Simon. 1992. European wild rodents as reservoir hosts of Borrelia burgdorferi: ecological and immunological aspects. V International Conference on Lyme Borreliosis, Arlington, USA, May 30-June 2, 1992. Abstract 293. Organizing Committee [eds.], Arlington.

Lebet, N. and L. Gern. 1994. Histological examination of Borrelia burgdorferi infections in unfed Ixodes ricinus nymphs. Exp. Appl. Acarol. 18: 177-183.

Leuba-Garcia, S., M. D. Kramer, R. Wallieh, and L. Gern. 1994. Characterization of Borrelia burgdorferi isolated from different organs of Ixodes ricinus ticks collected in nature. Zentralbl. Bakteriol. Hyg. 280: 468-475.

Miserez, V., L. Gern, and A. Aeschlimann. 1990. Borrelia burgdorferi in ticks of the canton Tessin (Switzerland). Parassitologia 32: 293-299.

Nakao, M., K. Miyamoto, and M. Fukunaga. 1994. Lyme disease spirochetes in Japan: enzootic transmission cycles in birds, rodents, and Ixodes persulcatus ticks. J. Infect. Dis. 170: 878-882.

Olsen, B., T.G.T. Jaenson, D. Duffy, and S. Bergström. 1994. Lyme disease borreliae in Ixodes uriae from the Northern and Southern Hemispheres. VI International Conference on Lyme Borreliosis, Bologna, Italy, June 19-22, 1994. Abstract P064 W. R. Cevenini, V. Sambri, and M. La Placa [eds.], Bologna.

Péter, O. 1990. Lyme borreliosis in the State of Valais, Switzerland. J. Int. Fed. Clin. Chem. 2: 121-124.

Péter, O. and A. G. Bretz. 1992. Polymorphism of outer surface proteins of Borrelia burgdorferi as a tool for classification. Zentralbl. Bakteriol. 277: 28-33.
Postic, D., M. V. Assous, P.A.D. Grimont, and G. Baranton. 1994. Diversity of Borrelia burgdorferi sensu lato evidenced by restriction fragment length polymorphism of $r f$ (5S)-rrl (23S) intergenic spacer amplicons. Int. J. Syst. Bacteriol. 44: 743-752.

Sinsky, R. J. and J. Piesman. 1989. Ear punch biopsy method for detection and isolation of Borrelia burgdorferi from rodents. J. Clin. Microbiol. 27: 17231727.

Towbin, H., H. Staehlin, and J. Gordon. 1979. Electrophoretic transfer of proteins from polyacrylamide gels to nitrocellulose sheets: procedure and some applications. Proc. Natl. Acad. Sci. U.S.A. 76: 43504354.

Wallich, R., S. E. Moter, M. D. Kramer, L. Gern, H. Hofmann, U. E. Schaible, and M. M. Simon. 1992. Untersuchungen zur genotypischen und phänotypischen Heterogenität von Borrelia burgdorferi, dem Erreger der Lyme-Borreliose, pp. 176-190. In D. Hassler, M. Kramer, M. Maiwald, W. Marget and L. Zöller [eds.], Infection, Fortschritte der Infektiologie. MMV Medizin Verlag, Munich.

Wilske, B., V. Preac-Mursic, G. Schierz, R. Kühbeck, A. G. Barbour, and M. D. Kramer. 1988. Antigenic variability of Borrelia burgdorferi. Ann. N.Y. Acad. Sci. 593: 126-143.

Zhioua, E., A. Aeschlimann, and L. Gern. 1994. Infection of field-collected Ixodes ricinus (Acari: Ixodidae) larvae with Borrelia burgdorferi in Switzerland. J. Med. Entomol. 31: 763-766.

Received for publication $19 \mathrm{July}$ 1994; accepted $30 \mathrm{De}-$ cember 1994 